\title{
Responding to the Call for Innovation: how do we develop health professionals' skills and operationalise innovation?
}

In a recent online open forum of the Association of University Programs in Health Administration (AUPHA) two of our American colleagues were discussing the need for a greater focus in health management curricula on 'transformation'. [1] They indicated that some time ago the American College of Healthcare Executives identified key skill areas for healthcare leaders as 'operational, people, and transformation', suggesting that good progress and focus on the first two had been achieved while more focus on the third was required. The discussion suggested that 'the area of transformation' needed to 'specifically include skills in intrapreneurship and also innovation'. [1] Intrapreneurship is a term used to distinguish activity within an organisation as opposed to wider concepts of entrepreneurship. Generally across health systems there is said to be 'a drive to roll out innovative models of care that will deliver better value for money and improve the quality of care'. [2, p.1] Innovation in health is in part being driven by legislation in the United Kingdom and the United States. There is of course, a similar emphasis in Australia. Adopting innovation in healthcare, is occurring 'at a scale... [ that] is increasingly viewed as crucial to the long-term sustainability of health systems.' [2, p.1]

Innovation is not a new concept. An article by Pierce and Delbecq [3] published in 1977, reviews research from as far back as the 1950s. These authors explore a range of definitions of innovations and opt to support that of Thompson [4] defining innovation as 'the generation, acceptance and implementation of new processes, products, or services for the first time within an organisation setting. [3, p.28] They go on to focus on 'initiation, adoption and implementation' as the phases of innovation. [3, p.29] In terms of predictive variables supportive of innovation they suggest that 'differentiation, professionalism, decentralisation, environmental uncertainty, large organisation size and interorganisational interdependence will be positively related with organisational innovation'. [3, p.30-32] 'Formalisation, stratification and age' are described as negatively related. [3, p.30-32] In terms of individual attitudes and values 'job satisfaction, involvement, performance dissatisfaction, intrinsic motivation and values of decision-makers' are positively related. [3, p.33] They suggest that organisations which are more organic in structure are more disposed to be innovative in the generation and acceptance phases but may well falter when it comes to the adoption phases, where they are not as successful, while mechanistic organisations are predisposed to resist change. [3]

Much has been researched and written about innovation including the view that 'innovation is often (mistakenly) regarded as uniformly positive' [5, p.i47] and that innovation is often adopted without adequate evaluation and proven benefits. [2] The paradoxes inherent in innovation are described as the 'uptake of the dubious, rejection of the good'; 'the wisdom and failings of democracy'; and 'health systems are never able to keep up'. [5, p.i47-i49] Innovation in healthcare needs to 'recognise the risk and costs of innovation, have effective systems for controlling its diffusion, study and collect data as it occurs, use adoption and implementation studies, clarify lines of authority, use 'phase one' studies to identify potentially unwanted, unhelpful effects and improve the training of health professionals to deal with the challenges'. [5, p.i50]

Plesk [6] in taking a complex adaptive approach to innovation and organisations in healthcare makes five recommendations for the adoption of innovation. These recommendations are summarised and abridged as: eschew mechanistic and coercive approaches; establish research and development (R\&D) functions within the organisation to focus on innovation; devote considerably more attention and effort to social networking in healthcare as being essential to the goal of spreading innovation; seek to establish a habit for change in healthcare organisations; develop better language and tools to support the creation of more receptive contexts for change. [6] Fitzgerald and colleagues also suggest from an organisational perspective that innovation is context specific. Primary health care (PHC), for example, is an abstract concept that doesn't fit easily with a notion of innovation in an organisational context as it 'has little history of collective, inter-practice collaboration' and that 'partnerships have to operate through consensus 
and persuasion rather than through hierarchy and power'. PHC operates in the context of networks rather than hierarchies. [7, p.226] There is also extensive evidence that adoption of innovation is difficult and that 'scientific research evidence needs translating to suit local contexts'. [7, p.226] These authors suggests that management requires a'facilitative, negotiative approach, that builds collaborative relationships and that opinion leaders are required to lead targeted improvements' with some focus on the values of those involved. [7, p.226]

Following a systematic review of the diffusion of innovations, Greenhalgh and colleagues [8] provide a definition of innovation in service delivery in organisation as:

A novel set of behaviours, routines, and ways of working that are directed at improving health outcomes, administrative efficiency, cost effectiveness, or users' experience and that are implemented by planned and coordinated actions. [8, p.582]

These same authors in their comprehensive review of innovation research pose some interesting questions yet to be adequately answered, such as:

How are 'good ideas' in local healthcare systems reinvented across systems and networks?

How can we identify bad ideas and prevent them and what is the nature of interpersonal influence and opinion leadership in the range of different professional and managerial groups?

What is the nature and extent of the social networks of different players in the health service (both clinical and nonclinical)?

Who are the individuals who act as champions for organizational innovations in health services?

Who are the individuals who act as boundary spanners among health service organizations? [8, p.618]

The above quotation demonstrates the complexity for individuals and organisations to become proficient in the innovation context because they raise questions for us all of:

To what extent do'restructuring' initiatives (popular in health service organizations) improve their ability to adopt, implement, and sustain innovations?

How can we improve the absorptive capacity of service organizations for new knowledge?

How can leaders of service organizations set about achieving a receptive context for change?

What is the process leading to long-term routinization ... of innovations? [8, pp 618-619]
A further meta-analysis of team level predictors of innovation at work by Hulsheger, Anderson and Salgado [9] suggests that 'team process variables display substantial and generalizable relationships with innovation.' [9, p.1137] The analysis suggests that there needs to be a focus on 'providing groups with high norms for innovation' in an 'open to change and error friendly' climate. Teams should have 'clearly stated, shared and visionary goals' and be interdependent in reaching them and their own personal goals. Communication and networking both also need to be enhanced. [9, p.1140]

Dopson, Fitzgerald and Ferlie [10] place the emphasis on context as an active component in the process of change and innovation. They suggest that for context to be receptive there needs to be the 'availability and engagement of local, credible and skilled opinion leaders; the presence of sound inter-professional relationships; an understanding of the structural characteristics and configurations of the various organisational characteristics, the support of senior management, albeit at a distance and; project and change management skills availability'. [10, p.228] They emphasise that leadership is more likely to be effective where: it is distributed; issues of professional power are understood; complex social relationships are acknowledged and discussed; talent from all corners is harnessed; and the contribution of different perspectives is valued. [10, p.229]

Innovation is currently proposed as a response to perceived crises of an ageing population, a growing chronic disease burden and ever increasing healthcare costs. However, Braithwaite and colleagues suggest that this quest for innovation is a direct consequence of the current healthcare model having reached the end of its innovation life cycle. That model is seen as 'predicated on industrial thinking and disease management' when what is required is a 'shift to a wellness-orientated system focused on performance and outcomes' and that this will need to be based on 'a new values based system' if we are to reinvent healthcare to be focussed on 'wellness and performance'. [11, p.259]

Innovation in healthcare is important in responding to more recent market and public sector performance regimes; because of the growth in health and biotechnologies; and to better enable diffusion of information. [12, p.78] Innovation is difficult in healthcare where professional autonomy and discretion exist; where systems are designed to co-ordinate problems and not easily allow innovation to occur; and where strong professional and political ties exist outside the organisation that have a propensity to influence internally. [12] Intrapreneurship is used by some to describe what occurs 
within the organisation as opposed to entrepreneurship that has the wider contexts of operating across organisations and the myriad of networks and collaborations that exist in healthcare. Some regard intrapreneurship as 'orientated towards organisational mission and goals' and 'to innovation in clinical processes....' [12, p.80]

Healthcare organisations that are serious about innovation need to do so from a governance perspective and view all health professionals, managers and leaders as innovators. They need to map and manage knowledge and operationalise innovation. The practice of innovation involves social engagement and learning. This requires the development of communities of practice and networks of practice both within the organisation and across organisational boundaries that can involve some distance between participants as distributed networks of practice (DNOP) that require proper support by organisations but also be given space and discretion to achieve their purpose. $[12,13]$

Innovation is not a simple concept easily adopted and managed and the curricula to be developed for health professionals and managers, cross paradigms and disciplines. Responding to the issues, challenges and questions posed by the literature and described herein, requires contributions from researchers and from those charged with operationalising innovation. This suggests that the learning might best be situated in cross discipline, participatory and collaborative, action-based research activities, involving health professionals and researchers working together in real life contexts. So like our colleagues mentioned at the start of this Editorial, how would you go about developing an adequate curriculum in your program or operationalising innovation in your organisation?

\section{DS Briggs}

Editor

\section{References}

1. AUPHA 2016. Association of University Programs in Health Administration - Open Forum on transformational leadership between B. Archer Concordia University and D. Berman, Walden University. Jan 11, 2016. Available from: https://mail.google.com/ mail/u/0/\#search/aupha+open/152345ce5e8f0324

2. Wilson PM, Boaden R, Harvey G. Plans to accelerate innovation in health systems are less than IDEAL. BMJ Quality \& Safety Online First. 2015. Available from: http://qualitysafety.bmj.com/content/ early/2015/12/23/bmjqs-2015-004605.full.pdf+html

3. Pierce JL, Delbecq AL, Organisation structure, individual attitudes and innovation. The Academy of Management Review. 1977; Jan. Available from: https://www.researchgate.net/publication/ 271688857

4. Thompson VA. Bureaucracy and Innovation. Administrative Science Quarterly. 1965;10:1-20.

5. Dixon-Woods M, Amalberti R, Goodman S, Bergman B, Glasziou P. Problems and promises of innovation: why healthcare needs to rethink its love/hate relationship with the new. BMJ Qual Saf. 2011; 20(Suppl 1):i47-i51. doi:10.1136/bmjqs.2010.046227.

6. Plesk P. Complexity and the adoption of Innovation in healthcare. Accelerating Quality Improvement in healthcare strategies to speed the diffusion of Evidence Based-innovations Conference Washington, D.C. January 2003. National Institute for Health Care Management Foundation National committee for Quality Health Care. Available from: http://www.nihcm-old.com/pdf/Plsek.pdf.

7. Fitzgerald I, Ferlie E, Hawkins C. Innovation in healthcare: how does credible evidence influence professionals? Health Soc Care Community. 2003;11(3):219-228.

8. Greenhalgh T, Glenn R, MacFarlane F, Bate P, Kyriakidou O. Diffusion of Innovations in Service Organisations: systematic review and recommendations. Milbank Q. 2004; 82(4):581-629).

9. Hulsheger UR, Anderson N, Salgado JF. Team-level predictors of Innovation at work: A comprehensive Meta- Analysis spanning three decades of research. Journal of Applied Psychology. 2009; 94(5):1128-1145.

10. Dopson S, Fitzgerald I, Ferlie E, Understanding change and innovation in healthcare settings: reconceptualising the active role of context. Journal of Change Management. 2008; 8(3-4): 213-231. Available from: http://www.tandfonline.com/doi/abs/ 10.1080/14697010802133577

11. Braithwaite J, Skinner CA, Döéry ML. A values based health system. Med J Aust. 2011; 194(5):259-262.

12. Lega F. Strategic, organisational and managerial issues related to innovation, entrepreneurship and intrapreneurship in the hospital context: Remarks from the Italian experience. Journal of Management and Marketing in Healthcare. 2009;2(1):77-93.

13. Briggs DS. Networks, democracy, innovation, pumpkins and pimples. A Pac J Health Manag. 2012;7(1):4-5. 